\title{
Editorials
}

\section{Protecting the health of doctors during the COVID-19 pandemic}

\section{COVID-19 AND THOSE MOST AT RISK OF SERIOUS ILLNESS}

On 11 March 2020, the World Health Organization (WHO) declared the COVID-19 outbreak a pandemic.' With a vaccine some time away, and no effective drug treatment currently available, the options for controlling the pandemic remain limited. ${ }^{2}$ The virus causing COVID-19, SARS-CoV-2, is spread mainly through droplets and is highly contagious. With $>170000$ cases and $>26000$ deaths, the UK has been among the worst affected countries globally. Tragically, >100 health and care workers are reported to have already died in the UK because of COVID-19, including several GPs. ${ }^{3}$ More deaths are inevitable unless urgent action is taken to reduce the risk of healthcare workers contracting COVID-19 infection in the workplace.

Research from countries such as China and Italy has shown that the risks of serious illness and death in people with COVID-19 infection are strongly associated with age, sex, and underlying medical problems ${ }^{4,5}$ Older people, men, and people with cardiometabolic risk factors (such as hypertension, coronary heart disease, diabetes, and obesityl have the highest death rates. ${ }^{6}$ In the UK, emerging evidence suggests that people from ethnic minority communities may also have a higher risk of death, for example, nearly all the doctors who have died from COVID-19 infection in the UK have been from ethnic minority groups. ${ }^{7.8}$

\section{THE RISKS TO HEALTHCARE WORKERS}

The deaths of so many healthcare workers have led to understandable anxiety among NHS staff. This anxiety has been compounded by the problems many staff have experienced in obtaining suitable personal protective equipment (PPE); and the changing guidance on the use of PPE. Because people with COVID-19 infection can be infective before symptoms start, all healthcare workers who undertake faceto-face clinical work are potentially at risk of infection; and not just those staff who

\section{when high-specification PPE is worn ... COVID-19 infections and deaths in healthcare workers both fall substantially.}

deal with suspected or confirmed cases of COVID-19. ${ }^{9}$ As well as leading to anxiety and stress, living with this continuous threat to health and life also affects the productivity of healthcare workers and how well they can care for patients.

One striking feature of the deaths among doctors in the UK has been the age of these doctors: most deaths have occurred in doctors aged $>60$ years. This raises questions about the government's campaign to encourage retired doctors to return to NHS roles. The high proportion of deaths that have occurred in doctors aged $>60$ suggests that the NHS should be very cautious about placing these doctors in front-line clinical roles where they may be at risk of contracting COVID-19 infection. There is a need for doctors to work in other roles - such as supporting the NHS 111 service in England. Older doctors could also take on roles in clinical care through telephone and video consultations. By taking on roles that do not involve direct clinical contact, these doctors would still be able to support the NHS but do this in low-risk settings.

To make informed decisions about the deployment of staff, we need better data on the risks of infection, serious illness, and death by personal characteristics - such as age, sex, underlying health problems, and ethnicity. This would allow the calculation of personalised risk profiles for healthcare workers and enable their employers to make rational decisions on how to deploy staff to minimise risks to their health. ${ }^{10}$ This would include redeployment to lowerrisk areas for doctors with a higher risk of serious illness and death.

\section{PROTECTING THE HEALTH OF DOCTORS AND HEALTHCARE WORKERS}

What else can we do to reduce the risks to doctors and other healthcare workers? The first step to reduce these risks is to minimise the number of people who are seen by clinicians in face-to-face consultations. General practices across the UK have already shifted to a model of working in which the majority of patient contacts are now dealt with by telephone or video consultation. This has been supplemented by the increased use of the NHS Electronic Prescribing Service (EPS) to send prescriptions directly to pharmacies; and the use of email to send documents such as fit notes to patients and death certificates to families. However, even with the dramatic shift to remote and electronic working, some face-to-face contacts with patients are still needed. Many areas have therefore established primary care Covid hubs' and 'Covid home visiting services' to see patients with suspected COVID-19 infection who need clinical assessment. However, evidence for their effectiveness is currently unavailable.

Wearing adequate PPE is also essential. Experience from China, for example, shows that when high-specification PPE is worn lsuch as FFP3 masks, face visors, and gowns), and where staff are trained to use this PPE correctly, COVID-19 infections and deaths in healthcare workers both fall substantially. ${ }^{11}$ Good infection control measures, such as regular cleaning of work surfaces, can also reduce the risk of transmission of infections in healthcare settings. ${ }^{12}$ Finally, doctors need to take measures to protect their own health, seeking appropriate medical care and isolating themselves promptly if they develop symptoms of possible COVID-19 infection.

In conclusion, we need to better protect the health of doctors and other healthcare workers during the COVID-19 pandemic. Key steps to take include developing the risks of serious illness and death ... are strongly associated with age, sex, and underlying medical problems. 
personalised risk profiles for NHS staff, minimising clinical contact (particularly for older, male doctors; and those doctors with underlying health problems), and ensuring that all healthcare workers have access to appropriate high-quality PPE and are trained to use this PPE correctly.

\section{Azeem Majeed,}

Professor of Primary Care and Honorary Consultant in Public Health, Department of Primary Care and Public Health, School of Public Health, Imperial College London, London.

\section{Mariam Molokhia,}

Clinical Reader in Epidemiology and Primary Care, School of Population Health and Environmental. Sciences, King's College London, London.

\section{Bharat Pankhania,}

Senior Clinical Lecturer, College of Medicine and Health, University of Exeter, Exeter.

\section{Kaveh Asanati,}

Honorary Clinical Senior Lecturer and Consultant Occupational Physician, National Heart and Lung Institute, Faculty of Medicine, Imperial College London, London.

\section{Funding}

This article received no specific grant from any funding agency in the public, commercial, or notfor-profit sectors.

\section{Provenance}

Commissioned; not externally peer reviewed.

\section{Competing interests}

Bharat Pankhania is a former consultant in communicable diseases control with Public Health England. The other authors have declared no competing interests.

\section{Acknowledgements}

Azeem Majeed is supported by the National Institute for Health Research (NIHR) NW London Applied Research Collaboration. Mariam Molokhia is supported by the NIHR Biomedical Research Centre at Guy's and St Thomas' National Health Service Foundation Trust and King's College London. The views expressed in the article are those of the authors.

DOI: https://doi.org/10.3399/bjgp20X709925

\section{ADDRESS FOR CORRESPONDENCE}

\section{Azeem Majeed}

Department of Primary Care and Public Health, Imperial College London, 3rd Floor, Reynolds Building, Charing Cross Campus, St Dunstan's Road, London W6 8RP, UK.

\section{Email: a.majeed囚imperial.ac.uk}

aAzeem_Majeed

\section{REFERENCES}

1. World Health Organization. Rolling updates on coronavirus disease (COVID-19). https:// www.who.int/emergencies/diseases/novelcoronavirus-2019/events-as-they-happen (accessed 1 May 2020).

2. Adams JG. Walls RM. Supporting the health care workforce during the COVID-19 global epidemic. JAMA 2020; 323(15): 1439-1440. DOI: 10.1001/jama.2020.3972.

3. Coronavirus: remembering $100 \mathrm{NHS}$ and healthcare workers who have died. BBC News 2020; 28 Apr: https://www.bbc.com/ news/amp/health-52242856 laccessed 1 May 2020).

4. Novel Coronavirus Pneumonia Emergency Response Epidemiology Team. The epidemiological characteristics of an outbreak of 2019 novel coronavirus diseases (COVID19) in China. [Article in Chinese]. Chinese Center for Disease Control and Prevention Weekly 2020; 41(2): 145-151.

5. Onder G, Rezza G, Brusaferro S. Case-fatality rate and characteristics of patients dying in relation to COVID-19 in Italy. JAMA 2020; DOI: 10.1001/jama.2020.4683

6. Osama T, Pankhania B, Majeed A. Protecting older people from COVID-19: should the United Kingdom start at age 60? J R Soc Med 2020; DOI: 10.1177/0141076820921107. [Epub ahead of print]

7. Pareek M, Bangash MN, Pareek N, et al. Ethnicity and COVID-19: an urgent public health research priority. Lancet 2020; DOI: 10.1016/S0140-6736(20)30922-3. [Epub ahead of print].

8. Khunti K, Singh AK, Pareek M, Hanif W. Is ethnicity linked to incidence or outcomes of COVID-19? BMJ 2020; 369: m1548.

9. Gandhi M, Yokoe DS, Havlir DV. Asymptomatic transmission, the Achilles heel of current strategies to control COVID-19. N Engl J Med 2020; DOI: 10.1056/NEJMe2009758. [Epub ahead of print].

10. Majeed A, Asanati K. Improving workplace health in the NHS. BMJ 2020; 368: m850.

11. Zhan M, Qin Y, Xue X, Zhu S. Death from COVID-19 of 23 health care workers in China. N Engl J Med 2020; DOI: 10.1056/ NEJMc2005696. [Epub ahead of print].

12. World Health Organization. Infection prevention and control during health care when novel coronavirus (nCoV) infection is suspected. 2020. https://www.who.int/ publications-detail/infection-preventionand-control-during-health-care-whennovel-coronavirus-(ncov)-infection-issuspected-20200125 (accessed 1 May 2020). 